\title{
On an open question of Takahashi for nonspreading mappings in Banach spaces
}

Eskandar Naraghirad*

Dedicated to Professor Wataru Takahashi on the occasion of his seventieth birthday

"Correspondence:

eskandarrad@gmail.com; esnaraghirad@mail.yu.ac.ir

Department of Mathematics, Yasouj University, Yasouj, 75918, Iran

Department of Applied

Mathematics, National Sun Yat-Sen

University, Kaohsiung, 804, Taiwan

\begin{abstract}
In this paper, we first introduce a new class of mappings called asymptotically nonspreading mappings and establish weak and strong convergence theorems of the iterative sequences generated by these mappings in a real Banach space. We modify Halpern's iterations for finding a fixed point of an asymptotically nonspreading mapping and provide an affirmative answer to an open problem posed by Kurokawa and Takahashi in their final remark of (Kurokawa and Takahashi in Nonlinear Anal. 73:1562-1568, 2010) for nonspreading mappings. Furthermore, we investigate the approximation of common fixed points of asymptotically nonspreading mappings and nonexpansive mappings and derive a strong convergence theorem by a new hybrid method for these mappings. Our results improve and generalize many known results in the current literature.
\end{abstract}

MSC: $47 \mathrm{H} 10 ; 37 \mathrm{C} 25$

Keywords: asymptotically nonspreading mapping; fixed point; weak convergence; strong convergence; sunny nonexpansive retraction

\section{Introduction}

Throughout this paper, we denote the set of real numbers and the set of positive integers by $\mathbb{R}$ and $\mathbb{N}$, respectively. Let $E$ be a Banach space with the norm $\|\cdot\|$ and the dual space $E^{*}$. The modulus $\delta$ of convexity of $E$ is denoted by

$$
\delta(\epsilon)=\inf \left\{1-\frac{\|x+y\|}{2}:\|x\| \leq 1,\|y\| \leq 1,\|x-y\| \geq \epsilon\right\}
$$

for every $\epsilon$ with $0 \leq \epsilon \leq 2$. A Banach space $E$ is said to be uniformly convex if $\delta(\epsilon)>0$ for every $\epsilon>0$. Let $S_{E}=\{x \in E:\|x\|=1\}$. The norm of $E$ is said to be Gâteaux differentiable if for each $x, y \in S_{E}$, the limit

$$
\lim _{t \rightarrow 0} \frac{\|x+t y\|-\|x\|}{t}
$$

exists. In this case, $E$ is called smooth. If the limit (1.1) is attained uniformly in $x, y \in S_{E}$, then $E$ is called uniformly smooth. The Banach space $E$ is said to be strictly convex if $\left\|\frac{x+y}{2}\right\|<1$ whenever $x, y \in S_{E}$ and $x \neq y$. It is well known that $E$ is uniformly convex if and only if $E^{*}$ is uniformly smooth. It is also known that if $E$ is reflexive, then $E$ is strictly convex if and only if $E^{*}$ is smooth; for more details, see [1]. When $\left\{x_{n}\right\}_{n \in \mathbb{N}}$ is a sequence in the Banach space $E$,

(c) 2013 Naraghirad; licensee Springer. This is an Open Access article distributed under the terms of the Creative Commons Attribution License (http://creativecommons.org/licenses/by/2.0), which permits unrestricted use, distribution, and reproduction in any medium, provided the original work is properly cited. 
we denote the strong convergence of $\left\{x_{n}\right\}_{n \in \mathbb{N}}$ to $x \in E$ by $x_{n} \rightarrow x$ and the weak convergence by $x_{n} \rightarrow x$. For any sequence $\left\{x_{n}^{*}\right\}_{n \in \mathbb{N}}$ in $E^{*}$, we denote the strong convergence of $\left\{x_{n}^{*}\right\}_{n \in \mathbb{N}}$ to $x^{*} \in E^{*}$ by $x_{n}^{*} \rightarrow x^{*}$, the weak convergence by $x_{n}^{*} \rightarrow x^{*}$ and the weak-star convergence by $x_{n}^{*} \rightarrow^{*} x^{*}$. The normalized duality mapping $J: E \rightarrow 2^{E^{*}}$ is defined by

$$
J(x)=\left\{f \in E^{*}:\langle x, f\rangle=\|x\|^{2},\|x\|=\|f\|\right\}, \quad \forall x \in E .
$$

Now, we define a mapping $\rho:[0, \infty) \rightarrow[0, \infty)$, the modulus of smoothness of $E$, as follows:

$$
\rho(t)=\sup \left\{\frac{1}{2}(\|x+y\|+\|x-y\|)-1: x, y \in E,\|x\|=1,\|y\|=t\right\} .
$$

It is well known that $E$ is uniformly smooth if and only if $\lim _{t \rightarrow 0} \frac{\rho(t)}{t}=0$. Let $q \in \mathbb{R}$ be such that $1<q \leq 2$. Then a Banach space $E$ is said to be q-uniformly smooth if there exists a constant $c_{q}>0$ such that $\rho(t) \leq c_{q} t^{q}$ for all $t>0$. If a Banach space $E$ admits a sequentially continuous duality mapping $J$ from weak topology to weak-star topology, then $J$ is singlevalued and also $E$ is smooth; see [2] for more details. In this case, the normalized duality mapping $J$ is said to be weakly sequentially continuous, i.e., if $\left\{x_{n}\right\}_{n \in \mathbb{N}} \subset E$ is a sequence with $x_{n} \rightarrow x \in E$, then $J\left(x_{n}\right) \rightarrow^{*} J(x)$ [2]. A Banach space $E$ is said to satisfy the Opial property [3] if for any weakly convergent sequence $\left\{x_{n}\right\}_{n \in \mathbb{N}}$ in $E$ with weak limit $x$,

$$
\limsup _{n \rightarrow \infty}\left\|x_{n}-x\right\|<\limsup _{n \rightarrow \infty}\left\|x_{n}-y\right\|
$$

for all $y \in E$ with $y \neq x$. It is well known that all Hilbert spaces, all finite dimensional Banach spaces and the Banach spaces $l^{p}(1 \leq p<\infty)$ satisfy the Opial property; see, for example, [2,3]. It is also known that if $E$ admits a weakly sequentially continuous duality mapping, then $E$ is smooth and enjoys the Opial property; see [2] for more details.

Let $C$ be a nonempty subset of a real Banach space $E$, and let $T: C \rightarrow E$ be a mapping. We denote by $F(T)$ the set of fixed points of $T$, i.e., $F(T)=\{x \in C: T x=x\}$. A mapping $T: C \rightarrow E$ is said to be nonexpansive if $\|T x-T y\| \leq\|x-y\|$ for all $x, y \in C$. A mapping $T: C \rightarrow E$ is said to be quasi-nonexpansive if $F(T) \neq \emptyset$ and $\|T x-y\| \leq\|x-y\|$ for all $x \in C$ and $y \in F(T)$. Let $C$ be a nonempty, closed and convex subset of a Hilbert space $H$ and $x \in H$. Then there exists a unique nearest point $z \in C$ such that $\|x-z\|=\inf _{y \in C}\|x-y\|$. We denote such a correspondence by $z=P_{C} x$. The mapping $P_{C}$ is called metric projection of $H$ onto $C$.

The concept of nonexpansivity plays an important role in the study of Mann-type iteration for finding fixed points of a mapping $T: C \rightarrow C$, where $C$ is a closed and convex subset of a Banach space $E$. Recall that the Mann-type iteration [4] is given by the following formula

$$
x_{n+1}=\left(1-\beta_{n}\right) x_{n}+\beta_{n} T x_{n}, \quad x_{1} \in C .
$$

Here, $\left\{\beta_{n}\right\}_{n \in \mathbb{N}}$ is a sequence of real numbers in $[0,1]$ satisfying some appropriate conditions. A more general iteration scheme is the Halpern iteration, given by

$$
\left\{\begin{array}{l}
u \in E, \quad x_{1} \in C \quad \text { chosen arbitrarily, } \\
y_{n}=\left(1-\beta_{n}\right) x_{n}+\beta_{n} T x_{n} \\
x_{n+1}=\alpha_{n} u+\left(1-\alpha_{n}\right) y_{n}
\end{array}\right.
$$


where the sequences $\left\{\beta_{n}\right\}_{n \in \mathbb{N}}$ and $\left\{\alpha_{n}\right\}_{n \in \mathbb{N}}$ satisfy some appropriate conditions. In particular, when all $\alpha_{n}=0$, the Halpern iteration (1.3) becomes the standard Mann iteration (1.2). The construction of fixed points of nonexpansive mappings via Halpern's algorithm [5] has been extensively investigated recently in the current literature (see, for example, [6] and the references therein). Numerous results have been proved on Mann and Halpern's iterations for nonexpansive mappings in Hilbert and Banach spaces (see, e.g., [6-14]).

Let $E$ be a smooth, strictly convex and reflexive Banach space, and let $J$ be the normalized duality mapping of $E$. Let $C$ be a nonempty, closed and convex subset of $E$. The generalized projection $\Pi_{C}$ from $E$ onto $C$ is denoted by

$$
\Pi_{C}(x)=\underset{y \in C}{\arg \min } \phi(y, x)
$$

for all $x \in E$, where $\phi(x, y)=\|x\|^{2}-2\langle x, J y\rangle+\|y\|^{2}$ for all $x, y \in E$.

Following Kohsaka and Takahashi $[15,16]$ (see also [16-21]), a mapping $T: C \rightarrow C$ is said to be nonspreading if

$$
\phi(T x, T y)+\phi(T y, T x) \leq \phi(T x, y)+\phi(T y, x)
$$

for all $x, y \in C$, where $\phi(x, y)=\|x\|^{2}-2\langle x, J y\rangle+\|y\|^{2}, \forall x, y \in E$. Observe that if $E$ is a real Hilbert space, then $J$ is the identity mapping and $\phi(x, y)=\|x\|^{2}-2\langle x, y\rangle+\|y\|^{2}=\|x-y\|^{2}$.

Recently, Kurakawa and Takahashi [17] proved the following fixed point theorem for nonspreading mappings in a Hilbert space.

Theorem 1.1 [17] Let C be a nonempty, closed and convex subset of a real Hilbert space $H$. Let $T: C \rightarrow C$ be a nonspreading mapping with $F(T) \neq \emptyset$. Suppose that $\left\{x_{n}\right\}_{n \in \mathbb{N}}$ is a sequence generated by $x_{1}=x \in C, u \in C$ and

$$
x_{n+1}=\gamma_{n} u+\left(1-\gamma_{n}\right) \frac{1}{n} \sum_{k=0}^{n-1} T^{k} x_{n}, \quad \forall n \in \mathbb{N},
$$

where $0 \leq \gamma_{n} \leq 1, \lim _{n \rightarrow \infty} \gamma_{n}=0$ and $\sum_{n=1}^{\infty} \gamma_{n}=\infty$. Then $\left\{x_{n}\right\}_{n \in \mathbb{N}}$ converges strongly to $P_{F(T)} u$, where $P_{F(T)}$ is the metric projection of $H$ onto $F(T)$.

Kurokawa and Takahashi studied strong convergence theorems for nonspreading mappings and posed the following open problem in their final remark of [17].

Question 1.1 Is there any strong convergence theorem of Halpern type for nonspreading mappings in a Hilbert space $H$ ?

By using the iterative schemes proposed by Moudafi [8], Iemoto and Takahashi [18] studied the approximation of common fixed points of nonexpansive mappings and nonspreading mappings in a Hilbert space and proved the following strong convergence theorem.

Theorem 1.2 Let $C$ be a nonempty, closed and convex subset of a Hilbert space H. Let $S: C \rightarrow C$ be a nonspreading mapping, and let $T: C \rightarrow C$ be a nonexpansive mapping 
such that $F:=F(S) \cap F(T) \neq \emptyset$. Define a sequence $\left\{x_{n}\right\}_{n \in \mathbb{N}}$ as follows:

$$
\left\{\begin{array}{l}
x_{1} \in C \quad \text { chosen arbitrarily, } \\
x_{n+1}=\left(1-\alpha_{n}\right) x_{n}+\alpha_{n}\left(\beta_{n} S x_{n}+\left(1-\beta_{n}\right) T x_{n}\right)
\end{array}\right.
$$

for all $n \in \mathbb{N}$, where $\left\{\alpha_{n}\right\}_{n \in \mathbb{N}},\left\{\beta_{n}\right\}_{n \in \mathbb{N}} \subset[0,1]$. Then the following hold:

(i) If $\lim _{n \rightarrow \infty} \alpha_{n}\left(1-\alpha_{n}\right)>0$ and $\sum_{n=1}^{\infty}\left(1-\beta_{n}\right)<\infty$, then $\left\{x_{n}\right\}_{n \in \mathbb{N}}$ converges weakly to $v \in F(S)$;

(ii) If $\sum_{n=1}^{\infty} \alpha_{n}\left(1-\alpha_{n}\right)=\infty$ and $\sum_{n=1}^{\infty} \beta_{n}<\infty$, then $\left\{x_{n}\right\}_{n \in \mathbb{N}}$ converges weakly to $v \in F(T)$;

(iii) If $\lim _{n \rightarrow \infty} \alpha_{n}\left(1-\alpha_{n}\right)>0$ and $\lim _{n \rightarrow \infty} \beta_{n}\left(1-\beta_{n}\right)>0$, then $\left\{x_{n}\right\}_{n \in \mathbb{N}}$ converges weakly to $v \in F(S) \cap F(T)$.

Now, we are in a position to introduce the following new class of nonspreading-type mappings in a Banach space.

Definition 1.1 Let $E$ be a real Banach space. A mapping $T: D(T) \subset E \rightarrow E$ is said to be asymptotically nonspreading (for short ANS) if

$$
\left\|T^{n} x-T^{n} y\right\|^{2} \leq\|x-y\|^{2}+2\left\langle x-T^{n} x, J\left(y-T^{n} y\right)\right\rangle
$$

for all $x, y \in D(T)$ and $n \in \mathbb{N}$. The mapping $T$ is called nonspreading if

$$
\|T x-T y\|^{2} \leq\|x-y\|^{2}+2\langle x-T x, J(y-T y)\rangle
$$

for all $x, y \in D(T)$, where $D(T)$ is the domain of $T$ and $J$ is the normalized duality mapping of $E$.

Example 1.1 Let $T:[0,2] \rightarrow[0,2]$ be defined by

$$
T x= \begin{cases}0 & \text { if } x \in[0,2) \\ 1 & \text { if } x=2\end{cases}
$$

Then $T$ is an asymptotically nonspreading mapping with $F(T)=\{0\}$. Indeed, for any $x \in$ $[0,2)$ and $y=2$, we have $T x=0, T y=1, T^{n} x=T^{n} y=0$ for all $n \geq 2$. We define the function $f: \mathbb{R} \rightarrow \mathbb{R}$ by

$$
f(x)=(x-2)^{2}+2 x, \quad \forall x \in \mathbb{R} .
$$

Then we have

$$
f^{\prime}(x)=2(x-2)+2=0 \quad \Longrightarrow \quad x=1
$$

where $f^{\prime}(x)$ is the derivative of $f$ at $x$. This implies that

$$
3=f(1) \leq f(x), \quad \forall x \in \mathbb{R} .
$$


Observe now that

$$
|T x-T y|^{2}=|1-0|^{2} \leq|x-2|^{2}+2 x=(x-2)^{2}+2 x .
$$

On the other hand, for any $n \geq 2$, we have

$$
\left|T^{n} x-T^{n} y\right|^{2}=0 \leq|x-2|^{2}+4 x=(x-2)^{2}+4 x .
$$

The other cases can be verified similarly. It is worth mentioning that $T$ is neither nonexpansive nor continuous.

In this paper, we first introduce a new class of asymptotically nonspreading mappings and establish weak and strong convergence theorems of the iterative sequences generated by these mappings in a real Banach space. We modify Mann and Halpern's iterations for finding a fixed point of an asymptotically nonspreading mapping and provide an affirmative answer to Question 1.1. Furthermore, we study the approximation of common fixed points of asymptotically nonspreading mappings and nonexpansive mappings and derive a strong convergence theorem by a new hybrid method for these mappings. Our results improve and generalize many known results in the current literature; see, for example, [17].

\section{Preliminaries}

In this section, we collect some lemmas which will be used in the proofs for the main results in the next sections.

Let $C$ and $D$ be nonempty subsets of a real Banach space $E$ with $D \subset C$. A mapping $Q_{D}: C \rightarrow D$ is said to be sunny if

$$
Q_{D}\left(Q_{D} x+t\left(x-Q_{D} x\right)\right)=Q_{D} x
$$

for each $x \in E$ and $t \geq 0$. A mapping $Q_{D}: C \rightarrow D$ is said to be a retraction if $Q_{D} x=x$ for each $x \in C$.

Lemma 2.1 [22] Let $C$ and $D$ be nonempty subsets of a real Banach space $E$ with $D \subset C$, and let $Q_{D}: C \rightarrow D$ be a retraction from $C$ into $D$. Then $Q_{D}$ is sunny and nonexpansive if and only if

$$
\left\langle z-Q_{D}(z), J\left(y-Q_{D}(z)\right)\right\rangle \leq 0
$$

for all $z \in C$ and $y \in D$, where $J$ is the normalized duality mapping of $E$.

Lemma 2.2 [22] Let E be a real Banach space and J be the normalized duality mapping of E. Then

$$
\|x+y\|^{2} \leq\|x\|^{2}+2\langle y, J(x+y)\rangle
$$

for all $x, y \in E$. 
Proposition 2.1 [19] Let $C$ be a nonempty, closed and convex subset of a real Hilbert space $H$, and let $T: C \rightarrow C$ be a nonspreading mapping. If $F(T) \neq \emptyset$, then it is closed and convex.

Let $C$ be a nonempty, closed and convex subset of a Banach space $E$, and let $\left\{x_{n}\right\}_{n \in \mathbb{N}}$ be a bounded sequence in $E$. For any $x \in E$, we set

$$
r\left(x,\left\{x_{n}\right\}_{n \in \mathbb{N}}\right)=\limsup _{n \rightarrow \infty}\left\|x-x_{n}\right\| .
$$

The asymptotic radius of $\left\{x_{n}\right\}_{n \in \mathbb{N}}$ relative to $C$ is defined by

$$
r\left(C,\left\{x_{n}\right\}_{n \in \mathbb{N}}\right)=\inf \left\{r\left(x,\left\{x_{n}\right\}_{n \in \mathbb{N}}\right): x \in C\right\} .
$$

The asymptotic center of $\left\{x_{n}\right\}_{n \in \mathbb{N}}$ relative to $C$ is the set

$$
A\left(C,\left\{x_{n}\right\}_{n \in \mathbb{N}}\right)=\left\{x \in C: r\left(x,\left\{x_{n}\right\}_{n \in \mathbb{N}}\right)=r\left(C,\left\{x_{n}\right\}_{n \in \mathbb{N}}\right)\right\} .
$$

It is well known that, in a uniformly convex Banach space $E, A\left(C,\left\{x_{n}\right\}_{n \in \mathbb{N}}\right)$ consists of exactly one point; see $[3,22]$.

Lemma 2.3 [23] Let $\left\{s_{n}\right\}_{n \in \mathbb{N}}$ be a sequence of nonnegative real numbers satisfying the inequality

$$
s_{n+1} \leq\left(1-\gamma_{n}\right) s_{n}+\gamma_{n} \delta_{n}, \quad \forall n \geq 1
$$

where $\left\{\gamma_{n}\right\}_{n \in \mathbb{N}}$ and $\left\{\delta_{n}\right\}_{n \in \mathbb{N}}$ satisfy the conditions:

(i) $\left\{\gamma_{n}\right\}_{n \in \mathbb{N}} \subset[0,1]$ and $\sum_{n=1}^{\infty} \gamma_{n}=\infty$ or, equivalently, $\prod_{n=1}^{\infty}\left(1-\gamma_{n}\right)=0$;

(ii) $\limsup _{n \rightarrow \infty} \delta_{n} \leq 0$, or

(ii') $\sum_{n=1}^{\infty} \gamma_{n} \delta_{n}<\infty$.

Then $\lim _{n \rightarrow \infty} s_{n}=0$.

Lemma 2.4 [24] Let $\left\{a_{n}\right\}_{n \in \mathbb{N}}$ be a sequence of real numbers such that there exists a subsequence $\left\{n_{i}\right\}_{i \in \mathbb{N}}$ of $\{n\}_{n \in \mathbb{N}}$ such that $a_{n_{i}}<a_{n_{i}+1}$ for all $i \in \mathbb{N}$. Then there exists a subsequence $\left\{m_{k}\right\}_{k \in \mathbb{N}} \subset \mathbb{N}$ such that $m_{k} \rightarrow \infty$ and the following properties are satisfied by all (sufficiently large) numbers $k \in \mathbb{N}$ :

$$
a_{m_{k}} \leq a_{m_{k}+1} \text { and } a_{k} \leq a_{m_{k}+1}
$$

In fact, $m_{k}=\max \left\{j \leq k: a_{j}<a_{j+1}\right\}$.

Lemma $2.5[25,26]$ Let E be a uniformly convex Banach space and $B_{r}:=\{x \in E:\|x\| \leq r\}$, $r>0$. Then there exists a continuous, strictly increasing and convex function $g:[0, \infty) \rightarrow$ $[0, \infty)$ with $g(0)=0$ such that

$$
\|\lambda x+\beta y+\gamma z\|^{2} \leq \lambda\|x\|^{2}+\beta\|y\|^{2}+\gamma\|z\|^{2}-\lambda \beta g(\|x-y\|)
$$

for all $x, y, z \in B_{r}$ and all $\lambda, \beta, \gamma \in[0,1]$ with $\lambda+\beta+\gamma=1$. 


\section{Fixed point theorems}

In the following, we present the existence theorems of fixed points of asymptotically nonspreading mappings in a Banach space.

Theorem 3.1 Let $C$ be a nonempty, closed and convex subset of a uniformly convex Banach space E. Let $T: C \rightarrow C$ be an asymptotically nonspreading mapping. Then the following assertions are equivalent.

(1) The fixed point set $F(T) \neq \emptyset$.

(2) There exists a bounded sequence $\left\{x_{n}\right\}_{n \in \mathbb{N}}$ in $C$ such that $\liminf _{n \rightarrow \infty}\left\|x_{n}-T x_{n}\right\|=0$.

Proof The implication (1) $\Longrightarrow(2)$ is obvious. For the converse implication, suppose that there exists a bounded sequence $\left\{x_{n}\right\}_{n \in \mathbb{N}}$ in $C$ such that $\liminf _{n \rightarrow \infty}\left\|x_{n}-T x_{n}\right\|=0$. Consequently, there is a bounded subsequence $\left\{T x_{n_{k}}\right\}_{k \in \mathbb{N}}$ of $\left\{T x_{n}\right\}_{n \in \mathbb{N}}$ such that $\lim _{k \rightarrow \infty} \| T x_{n_{k}}-$ $x_{n_{k}} \|=0$. Suppose $A\left(C,\left\{x_{n_{k}}\right\}_{k \in \mathbb{N}}\right)=\{z\}$. Let $M_{1}=\sup \left\{\left\|x_{n_{k}}\right\|,\left\|T x_{n_{k}}\right\|,\|z\|,\|T z\|: k \in \mathbb{N}\right\}<\infty$. Since $T$ is an asymptotically nonspreading mapping, we obtain

$$
\begin{aligned}
\left\|x_{n_{k}}-T z\right\|^{2} \leq & \left\|x_{n_{k}}-T x_{n_{k}}\right\|^{2}+\left\|T x_{n_{k}}-T z\right\|^{2}+2\left\|x_{n_{k}}-T x_{n_{k}}\right\|\left\|T x_{n_{k}}-T z\right\| \\
\leq & \left\|x_{n_{k}}-T x_{n_{k}}\right\|^{2}+\left\|T x_{n_{k}}-T z\right\|^{2}+2 M_{1}\left\|x_{n_{k}}-T x_{n_{k}}\right\| \\
\leq & \left\|x_{n_{k}}-T x_{n_{k}}\right\|^{2}+\left\|x_{n_{k}}-z\right\|^{2} \\
& +2\left\langle x_{n_{k}}-T x_{n_{k}}, J(z-T z)\right\rangle+2 M_{1}\left\|x_{n_{k}}-T x_{n_{k}}\right\| \\
\leq & \left\|x_{n_{k}}-T x_{n_{k}}\right\|^{2}+\left\|x_{n_{k}}-z\right\|^{2}+6 M_{1}\left\|x_{n_{k}}-T x_{n_{k}}\right\| .
\end{aligned}
$$

This implies that

$$
\begin{gathered}
\limsup _{k \rightarrow \infty}\left\|x_{n_{k}}-T z\right\|^{2} \leq \limsup _{k \rightarrow \infty}\left\|x_{n_{k}}-T x_{n_{k}}\right\|^{2}+\limsup _{k \rightarrow \infty}\left\|x_{n_{k}}-z\right\|^{2} \\
+6 M_{1} \limsup _{k \rightarrow \infty}\left\|x_{n_{k}}-T x_{n_{k}}\right\| .
\end{gathered}
$$

Thus we have

$$
r\left(T z,\left\{x_{n_{k}}\right\}_{k \in \mathbb{N}}\right)=\limsup _{k \rightarrow \infty}\left\|x_{n_{k}}-T z\right\| \leq \limsup _{k \rightarrow \infty}\left\|x_{n_{k}}-z\right\|=r\left(z,\left\{x_{n_{k}}\right\}_{k \in \mathbb{N}}\right) .
$$

This means that $T z \in A\left(C,\left\{x_{n_{k}}\right\}_{k \in \mathbb{N}}\right)$. By the uniform convexity of $E$, we conclude that $T z=$ $z$, which completes the proof.

The following result is an immediate consequence of Theorem 3.1.

Proposition 3.1 (Demiclosedness principle) Let C be a nonempty, closed and convex subset of a real uniformly convex Banach space E. Suppose that $T: C \rightarrow E$ is an asymptotically nonspreading mapping with $F(T) \neq \emptyset$. If $\left\{x_{n}\right\}_{n \in \mathbb{N}}$ is a sequence in $C$ that converges weakly to $x$ and if $\left\{(I-T) x_{n}\right\}_{n \in \mathbb{N}}$ converges strongly to 0 , then $x \in F(T)$.

Theorem 3.2 Let C be a nonempty, closed and convex subset of a uniformly convex Banach space E. Let $T: C \rightarrow C$ be an asymptotically nonspreading mapping which is uniformly asymptotically regular, i.e., $\lim _{n \rightarrow \infty}\left\|T^{n} x-T^{n+1} x\right\|=0$ for all $x \in C$. Then the following assertions are equivalent. 
(1) The fixed point set $F(T) \neq \emptyset$.

(2) There exists $x \in C$ such that the sequence $\left\{T^{n} x\right\}_{n \in \mathbb{N}}$ is bounded.

Proof The implication (1) $\Longrightarrow(2)$ is obvious. For the converse implication, suppose that there exists $x \in C$ such that the sequence $\left\{T^{n} x\right\}_{n \in \mathbb{N}}$ is bounded. Setting $u_{n}=T^{n} x$ for all $n \in \mathbb{N}$, the uniformly asymptotical regularity of $T$ assures that

$$
\lim _{n \rightarrow \infty}\left\|T u_{n}-u_{n}\right\|=\lim _{n \rightarrow \infty}\left\|T^{n+1} x-T^{n} x\right\|=0 .
$$

Since $\left\{u_{n}\right\}_{n \in \mathbb{N}}$ is bounded, in view of Theorem 3.1, we conclude that $F(T) \neq \emptyset$, which completes the proof.

Theorem 3.3 Let $C$ be a nonempty, closed and convex subset of a real Hilbert space H. Let $T: C \rightarrow C$ be a nonspreading mapping. Then the following assertions are equivalent.

(1) The fixed point set $F(T) \neq \emptyset$.

(2) There exists $x \in C$ such that the sequence $\left\{T^{n} x\right\}_{n \in \mathbb{N}}$ is bounded.

Proof It is obvious that (1) implies (2). Now, suppose that there exists $x \in C$ such that the sequence $\left\{T^{n} x\right\}_{n \in \mathbb{N}}$ is bounded. Put $x_{n+1}=T^{n} x=T x_{n}$ and $z_{n}=\frac{1}{n} \sum_{k=1}^{n} T^{k-1} x=\frac{1}{n} \sum_{k=1}^{n} x_{k}$ for all $n \in \mathbb{N}$. Continuing the same process as in the proof of Theorem 3.1 in [17], we conclude that $z_{n} \rightarrow z \in F(T)$ as $n \rightarrow \infty$, which completes the proof.

\section{Weak and strong convergence theorems}

In this section, we prove weak and strong convergence theorems for asymptotically nonspreading mappings in a Banach space.

Lemma 4.1 Let $C$ be a nonempty, closed and convex subset of a real Banach space E. Let $T: C \rightarrow C$ be an asymptotically nonspreading mapping. Let $\left\{x_{n}\right\}_{n \in \mathbb{N}}$ be a sequence in $C$ such that $\left\|x_{n}-x_{n+1}\right\| \rightarrow 0$ and $\left\|x_{n}-T^{n} x_{n}\right\| \rightarrow 0$ as $n \rightarrow \infty$. Then $\lim _{n \rightarrow \infty}\left\|x_{n}-T^{m} x_{n}\right\|=0$ for all $m \in \mathbb{N}$.

Proof We divide the proof into several steps.

Step 1. We claim that the following statements hold:

(a) $\lim _{n \rightarrow \infty}\left\|T^{n+1} x_{n}-T^{n+1} x_{n+1}\right\|=0$;

(b) $\lim _{n \rightarrow \infty}\left\|x_{n}-T^{n+1} x_{n}\right\|=0$;

(c) $\lim _{n \rightarrow \infty}\left\|T^{n} x_{n}-T^{n+1} x_{n}\right\|=0$.

Since $T$ is an asymptotically nonspreading mapping, we obtain

$$
\begin{aligned}
\left\|T^{n+1} x_{n}-T^{n+1} x_{n+1}\right\|^{2} & \leq\left\|x_{n}-x_{n+1}\right\|^{2}+2\left\langle x_{n}-T^{n+1} x_{n}, J\left(x_{n+1}-T^{n+1} x_{n+1}\right)\right\rangle \\
& \leq\left\|x_{n}-x_{n+1}\right\|^{2}+2\left\|x_{n}-T^{n+1} x_{n}\right\|\left\|x_{n+1}-T^{n+1} x_{n+1}\right\| .
\end{aligned}
$$

Due to the boundedness of $\left\{x_{n}\right\}_{n \in \mathbb{N}}$, we deduce that

$$
\lim _{n \rightarrow \infty}\left\|T^{n+1} x_{n}-T^{n+1} x_{n+1}\right\|=0 .
$$

Observe now that

$$
\left\|x_{n}-T^{n+1} x_{n}\right\| \leq\left\|x_{n}-x_{n+1}\right\|+\left\|x_{n+1}-T^{n+1} x_{n+1}\right\|+\left\|T^{n+1} x_{n+1}-T^{n+1} x_{n}\right\| .
$$


Thus we have

$$
\lim _{n \rightarrow \infty}\left\|x_{n}-T^{n+1} x_{n}\right\|=0
$$

This implies that

$$
\left\|T^{n} x_{n}-T^{n+1} x_{n}\right\| \leq\left\|T^{n} x_{n}-x_{n}\right\|+\left\|x_{n}-T^{n+1} x_{n}\right\| \rightarrow 0
$$

as $n \rightarrow \infty$.

Step 2. We prove the following assertions:

(d) $\lim _{n \rightarrow \infty}\left\|T^{n+1} x_{n}-T x_{n}\right\|=0$;

(e) $\lim _{n \rightarrow \infty}\left\|x_{n}-T x_{n}\right\|=0$.

Since $T$ is an asymptotically nonspreading mapping, we get

$$
\begin{aligned}
\left\|T^{n+1} x_{n}-T x_{n}\right\|^{2} & =\left\|T\left(T^{n} x_{n}\right)-T x_{n}\right\|^{2} \\
& \leq\left\|T^{n} x_{n}-x_{n}\right\|^{2}+2\left\langle T^{n} x_{n}-T^{n+1} x_{n}, J\left(x_{n}-T x_{n}\right)\right\rangle \\
& \leq\left\|T^{n} x_{n}-x_{n}\right\|^{2}+2\left\|T^{n} x_{n}-T^{n+1} x_{n}\right\|\left\|x_{n}-T x_{n}\right\| .
\end{aligned}
$$

Due to the boundedness of $\left\{x_{n}\right\}_{n \in \mathbb{N}}$ and in view of Step 1(c), we deduce that

$$
\lim _{n \rightarrow \infty}\left\|T^{n+1} x_{n}-T x_{n}\right\|=0
$$

Observe now that

$$
\left\|x_{n}-T x_{n}\right\| \leq\left\|x_{n}-T^{n+1} x_{n}\right\|+\left\|T^{n+1} x_{n}-T x_{n}\right\| \rightarrow 0
$$

as $n \rightarrow \infty$.

Step 3. We show that $\lim _{n \rightarrow \infty}\left\|T^{m-1} x_{n}-T^{m} x_{n}\right\|=0$ for all $m \in \mathbb{N}$.

To this end, we apply the principle of mathematical induction. In view of Step 2(e), for $m=1$, we deduce that $\lim _{n \rightarrow \infty}\left\|x_{n}-T x_{n}\right\|=0$. Now, suppose that for $m \in \mathbb{N}$,

$$
\lim _{n \rightarrow \infty}\left\|T^{m-1} x_{n}-T^{m} x_{n}\right\|=0
$$

We prove that

$$
\lim _{n \rightarrow \infty}\left\|T^{m} x_{n}-T^{m+1} x_{n}\right\|=0
$$

Since $T$ is an asymptotically nonspreading mapping, we have

$$
\begin{aligned}
\left\|T^{m} x_{n}-T^{m+1} x_{n}\right\|^{2} & =\left\|T\left(T^{m-1} x_{n}\right)-T\left(T^{m} x_{n}\right)\right\|^{2} \\
& \leq\left\|T^{m-1} x_{n}-T^{m} x_{n}\right\|^{2}+2\left\langle T^{m-1} x_{n}-T^{m} x_{n}, J\left(T^{m} x_{n}-T^{m+1} x_{n}\right)\right\rangle \\
& \leq\left\|T^{m-1} x_{n}-T^{m} x_{n}\right\|^{2}+2\left\|T^{m-1} x_{n}-T^{m} x_{n}\right\|\left\|T^{m} x_{n}-T^{m+1} x_{n}\right\| .
\end{aligned}
$$

Thus we have $\lim _{n \rightarrow \infty}\left\|T^{m-1} x_{n}-T^{m} x_{n}\right\|=0$ for all $m \in \mathbb{N}$. 
By the triangle inequality, we see that for any $m \in \mathbb{N}$,

$$
\left\|x_{n}-T^{m} x_{n}\right\| \leq\left\|x_{n}-T x_{n}\right\|+\left\|T x_{n}-T^{2} x_{n}\right\|+\cdots+\left\|T^{m-1} x_{n}-T^{m} x_{n}\right\| .
$$

In view of Steps 2 and 3, we conclude that $\lim _{n \rightarrow \infty}\left\|x_{n}-T^{m} x_{n}\right\|=0$ for all $m \in \mathbb{N}$. This completes the proof.

Theorem 4.1 Let $C$ be a nonempty, closed and convex subset of a uniformly convex Banach space $E$ with Opial property, and let $T: C \rightarrow C$ be an asymptotically nonspreading mapping such that $F(T) \neq \emptyset$. Assume that $\left\{\alpha_{n}\right\}_{n \in \mathbb{N}}$ is a sequence in $(0,1)$ such that $0<\delta \leq \alpha_{n} \leq 1-\delta<1$. Let $\left\{x_{n}\right\}_{n \in \mathbb{N}}$ be a sequence in $C$ generated by the modified Mann iteration process

$$
x_{n+1}=\left(1-\alpha_{n}\right) x_{n}+\alpha_{n} T^{n} x_{n}, \quad \forall n \in \mathbb{N} .
$$

Then the sequence $\left\{x_{n}\right\}_{n \in \mathbb{N}}$ generated by algorithm (4.1) converges weakly to an element of $F(T)$.

Proof Take any $p \in F(T)$ arbitrarily chosen. In view of Lemma 2.5, there exists a continuous, strictly increasing and convex function $g:[0, \infty) \rightarrow[0, \infty)$ with $g(0)=0$ such that

$$
\begin{aligned}
\left\|x_{n+1}-p\right\|^{2} & =\left\|\left(1-\alpha_{n}\right)\left(x_{n}-p\right)+\alpha_{n}\left(T^{n} x_{n}-p\right)\right\|^{2} \\
& \leq\left(1-\alpha_{n}\right)\left\|x_{n}-p\right\|^{2}+\alpha_{n}\left\|T^{n} x_{n}-p\right\|^{2}-\alpha_{n}\left(1-\alpha_{n}\right) g\left(\left\|x_{n}-T^{n} x_{n}\right\|\right) \\
& \leq\left(1-\alpha_{n}\right)\left\|x_{n}-p\right\|^{2}+\alpha_{n}\left\|x_{n}-p\right\|^{2}-\alpha_{n}\left(1-\alpha_{n}\right) g\left(\left\|x_{n}-T^{n} x_{n}\right\|\right) \\
& =\left\|x_{n}-p\right\|^{2}-\alpha_{n}\left(1-\alpha_{n}\right) g\left(\left\|x_{n}-T^{n} x_{n}\right\|\right) \\
& \leq\left\|x_{n}-p\right\|^{2}-\delta^{2} g\left(\left\|x_{n}-T^{n} x_{n}\right\|\right) .
\end{aligned}
$$

Since $\delta>0$, we have from (4.2) that

$$
\left\|x_{n+1}-p\right\| \leq\left\|x_{n}-p\right\|, \quad \forall n \in \mathbb{N} \text {. }
$$

This implies that $\lim _{n \rightarrow \infty}\left\|x_{n}-p\right\|$ exists and hence $\left\{x_{n}\right\}_{n \in \mathbb{N}}$ is bounded. Setting

$$
\lim _{n \rightarrow \infty}\left\|x_{n}-p\right\|=d
$$

it follows from (4.2) that

$$
\delta^{2} g\left(\left\|x_{n}-T^{n} x_{n}\right\|\right) \leq\left\|x_{n}-p\right\|^{2}-\left\|x_{n+1}-p\right\|^{2},
$$

which yields that $\lim _{n \rightarrow \infty}\left\|x_{n}-T^{n} x_{n}\right\|=0$. In view of (4.1), we see that

$$
\left\|x_{n+1}-x_{n}\right\|=\alpha_{n}\left\|x_{n}-T^{n} x_{n}\right\| \leq(1-\delta)\left\|x_{n}-T^{n} x_{n}\right\|, \quad \forall n \in \mathbb{N} .
$$

Thus we have $\lim _{n \rightarrow \infty}\left\|x_{n}-x_{n+1}\right\|=0$. Employing Proposition 3.1 and Lemma 4.1, we conclude that there exists $x \in F(T)$ such that $x_{n} \rightarrow x$ as $n \rightarrow \infty$, which completes the proof. 
Theorem 4.2 Let E be a real uniformly convex Banach space which admits the weakly sequentially continuous duality mapping $J$, and let $C$ be a nonempty, closed and convex subset of $E$. Let $T: C \rightarrow C$ be an asymptotically nonspreading mapping such that $F:=$ $F(T) \neq \emptyset$. Let $\left\{\alpha_{n}\right\}_{n \in \mathbb{N}}$ and $\left\{\beta_{n}\right\}_{n \in \mathbb{N}}$ be two sequences in $[0,1]$ satisfying the following control conditions:

(a) $\lim _{n \rightarrow \infty} \alpha_{n}=0$;

(b) $\sum_{n=1}^{\infty} \alpha_{n}=\infty$;

(c) $\liminf _{n \rightarrow \infty} \beta_{n}\left(1-\beta_{n}\right)>0$.

Let $\left\{x_{n}\right\}_{n \in \mathbb{N}}$ be a sequence generated by

$$
\left\{\begin{array}{l}
u \in C, \quad x_{1} \in C \quad \text { chosen arbitrarily, } \\
y_{n}=\left(1-\beta_{n}\right) x_{n}+\beta_{n} T^{n} x_{n} \\
x_{n+1}=\alpha_{n} u+\left(1-\alpha_{n}\right) y_{n} .
\end{array}\right.
$$

Then the sequence $\left\{x_{n}\right\}_{n \in \mathbb{N}}$ defined in (4.3) converges strongly to $Q_{F} u$, where $Q_{F}$ is the sunny nonexpansive retraction from $E$ onto $F$.

Proof We divide the proof into several steps.

Since $T$ is a quasi-nonexpansive mapping, so we have $F$ is closed and convex. Set

$$
z=Q_{F} u .
$$

Step 1. We prove that the sequences $\left\{x_{n}\right\}_{n \in \mathbb{N}},\left\{y_{n}\right\}_{n \in \mathbb{N}}$ and $\left\{T^{n} x_{n}\right\}_{n \in \mathbb{N}}$ are bounded.

We first show that $\left\{x_{n}\right\}_{n \in \mathbb{N}}$ is bounded.

Let $p \in F$ be fixed. In view of Lemma 2.5 , there exists a continuous, strictly increasing and convex function $g:[0, \infty) \rightarrow[0, \infty)$ with $g(0)=0$ such that

$$
\begin{aligned}
\left\|y_{n}-p\right\|^{2} & =\left\|\left(1-\beta_{n}\right) x_{n}+\beta_{n} T^{n} x_{n}-p\right\|^{2} \\
& \leq\left(1-\beta_{n}\right)\left\|x_{n}-p\right\|^{2}+\beta_{n}\left\|T^{n} x_{n}-p\right\|^{2}-\beta_{n}\left(1-\beta_{n}\right) g\left(\left\|x_{n}-T^{n} x_{n}\right\|\right) \\
& \leq\left(1-\beta_{n}\right)\left\|x_{n}-p\right\|^{2}+\beta_{n}\left\|x_{n}-p\right\|^{2}-\beta_{n}\left(1-\beta_{n}\right) g\left(\left\|x_{n}-T^{n} x_{n}\right\|\right) \\
& =\left\|x_{n}-p\right\|^{2}-\beta_{n}\left(1-\beta_{n}\right) g\left(\left\|x_{n}-T^{n} x_{n}\right\|\right) \\
& \leq\left\|x_{n}-p\right\|^{2} .
\end{aligned}
$$

This implies that

$$
\begin{aligned}
\left\|x_{n+1}-p\right\| & =\left\|\alpha_{n} u+\left(1-\alpha_{n}\right) y_{n}-p\right\| \\
& \leq \alpha_{n}\|u-p\|+\left(1-\alpha_{n}\right)\left\|y_{n}-p\right\| \\
& \leq \alpha_{n}\|u-p\|+\left(1-\alpha_{n}\right)\left\|x_{n}-p\right\| \\
& \leq \max \left\{\|u-p\|,\left\|x_{n}-p\right\|\right\} .
\end{aligned}
$$

By induction, we obtain

$$
\left\|x_{n+1}-p\right\| \leq \max \left\{\|u-p\|,\left\|x_{1}-p\right\|\right\}
$$


for all $n \in \mathbb{N}$. This implies that the sequence $\left\{\left\|x_{n}-p\right\|\right\}_{n \in \mathbb{N}}$ is bounded and hence the sequence $\left\{x_{n}\right\}_{n \in \mathbb{N}}$ is bounded. This, together with (4.3), implies that the sequences $\left\{y_{n}\right\}_{n \in \mathbb{N}}$ and $\left\{T^{n} x_{n}\right\}_{n \in \mathbb{N}}$ are bounded too.

Step 2 . We prove that for any $n \in \mathbb{N}$,

$$
\left\|x_{n+1}-z\right\|^{2} \leq\left(1-\alpha_{n}\right)\left\|x_{n}-z\right\|^{2}+2 \alpha_{n}\left\langle u-z, J\left(x_{n+1}-z\right)\right\rangle .
$$

Let us show (4.5). For each $n \in \mathbb{N}$, in view of (4.4), we obtain

$$
\left\|y_{n}-z\right\|^{2} \leq\left\|x_{n}-z\right\|^{2}-\beta_{n}\left(1-\beta_{n}\right) g\left(\left\|x_{n}-T^{n} x_{n}\right\|\right) .
$$

This implies that

$$
\begin{aligned}
\left\|x_{n+1}-z\right\|^{2} & =\left\|\alpha_{n} u+\left(1-\alpha_{n}\right) y_{n}-z\right\|^{2} \\
& \leq \alpha_{n}\|u-z\|^{2}+\left(1-\alpha_{n}\right)\left\|y_{n}-z\right\|^{2} \\
& \leq \alpha_{n}\|u-z\|^{2}+\left(1-\alpha_{n}\right)\left[\left\|x_{n}-z\right\|^{2}-\beta_{n}\left(1-\beta_{n}\right) g\left(\left\|x_{n}-T^{n} x_{n}\right\|\right)\right] .
\end{aligned}
$$

Let $M_{2}:=\sup \left\{\left|\|u-z\|^{2}-\left\|x_{n}-z\right\|^{2}\right|+\beta_{n}\left(1-\beta_{n}\right) g\left(\left\|x_{n}-T^{n} x_{n}\right\|\right): n \in \mathbb{N}\right\}$. It follows from (4.6) that

$$
\beta_{n}\left(1-\beta_{n}\right) g\left(\left\|x_{n}-T^{n} x_{n}\right\|\right) \leq\left\|x_{n}-z\right\|^{2}-\left\|x_{n+1}-z\right\|^{2}+\alpha_{n} M_{2}
$$

In view of Lemma 2.2 and (4.4), we obtain

$$
\begin{aligned}
\left\|x_{n+1}-z\right\|^{2} & =\left\|\alpha_{n} u+\left(1-\alpha_{n}\right) y_{n}-z\right\|^{2} \\
& =\left\|\alpha_{n}(u-z)+\left(1-\alpha_{n}\right)\left(y_{n}-z\right)\right\|^{2} \\
& \leq\left\|\left(1-\alpha_{n}\right)\left(y_{n}-z\right)\right\|^{2}+2\left\langle\alpha_{n}(u-z), J\left(x_{n+1}-z\right)\right\rangle \\
& =\left(1-\alpha_{n}\right)^{2}\left\|y_{n}-z\right\|^{2}+2\left\langle\alpha_{n}(u-z), J\left(x_{n+1}-z\right)\right\rangle \\
& \leq\left(1-\alpha_{n}\right)\left\|y_{n}-z\right\|^{2}+2\left\langle\alpha_{n}(u-z), J\left(x_{n+1}-z\right)\right\rangle \\
& =\left(1-\alpha_{n}\right)\left\|x_{n}-z\right\|^{2}+2 \alpha_{n}\left\langle u-z, J\left(x_{n+1}-z\right)\right\rangle .
\end{aligned}
$$

Step 3. We prove that $x_{n} \rightarrow z$ as $n \rightarrow \infty$.

We discuss the following two possible cases.

Case 1. If $\left\{\left\|x_{n}-z\right\|\right\}_{n \in \mathbb{N}}$ is eventually decreasing, then there exists $n_{0} \in \mathbb{N}$ such that the sequence $\left\{\left\|x_{n}-z\right\|\right\}_{n=n_{0}}^{\infty}$ is decreasing. Thus, the sequence $\left\{\left\|x_{n}-z\right\|\right\}_{n \in \mathbb{N}}$ is convergent and hence $\left\|x_{n}-z\right\|^{2}-\left\|x_{n+1}-z\right\|^{2} \rightarrow 0$ as $n \rightarrow \infty$. This, together with condition (c) and (4.7), implies that

$$
\lim _{n \rightarrow \infty} g\left(\left\|x_{n}-T^{n} x_{n}\right\|\right)=0
$$

From the properties of $g$, it follows that

$$
\lim _{n \rightarrow \infty}\left\|x_{n}-T^{n} x_{n}\right\|=0
$$


On the other hand, we have

$$
x_{n}-y_{n}=\beta_{n}\left(x_{n}-T^{n} x_{n}\right) \text { and } x_{n+1}-y_{n}=\alpha_{n}\left(u-y_{n}\right) \text {. }
$$

This implies that

$$
\lim _{n \rightarrow \infty}\left\|x_{n}-y_{n}\right\|=0 \text { and } \quad \lim _{n \rightarrow \infty}\left\|x_{n+1}-y_{n}\right\|=0
$$

By the triangle inequality, we conclude that

$$
\left\|x_{n+1}-x_{n}\right\| \leq\left\|x_{n+1}-y_{n}\right\|+\left\|y_{n}-x_{n}\right\| .
$$

It follows from (4.9) that

$$
\lim _{n \rightarrow \infty}\left\|x_{n+1}-x_{n}\right\|=0
$$

Exploiting Lemma 4.1, (4.8) and (4.10), we obtain

$$
\lim _{n \rightarrow \infty}\left\|x_{n}-T x_{n}\right\|=0
$$

Since $\left\{x_{n}\right\}_{n \in \mathbb{N}}$ is bounded, there exists a subsequence $\left\{x_{n_{i}}\right\}_{i \in \mathbb{N}}$ of $\left\{x_{n}\right\}_{n \in \mathbb{N}}$ such that $x_{n_{i}+1} \rightarrow$ $y \in C$ as $i \rightarrow \infty$. In view of Proposition 3.1 and (4.11), we conclude that $y \in F(T)$. This, together with Lemma 2.1, implies that

$$
\begin{aligned}
\limsup _{n \rightarrow \infty}\left\langle u-z, J\left(x_{n+1}-z\right)\right\rangle & =\lim _{i \rightarrow \infty}\left\langle u-z, J\left(x_{n_{i}+1}-z\right)\right\rangle \\
& =\langle u-z, J(y-z)\rangle \\
& \leq 0 .
\end{aligned}
$$

Thus we have the desired result by Lemma 2.3 .

Case 2. If $\left\{\left\|x_{n}-z\right\|\right\}_{n \in \mathbb{N}}$ is not eventually decreasing, then there exists a subsequence $\left\{n_{i}\right\}_{i \in \mathbb{N}}$ of $\{n\}_{n \in \mathbb{N}}$ such that

$$
\left\|x_{n_{i}}-z\right\|<\left\|x_{n_{i}+1}-z\right\|
$$

for all $i \in \mathbb{N}$. In view of Lemma 2.4, there exists a nondecreasing sequence $\left\{m_{k}\right\}_{k \in \mathbb{N}} \subset \mathbb{N}$ such that $m_{k} \rightarrow \infty$

$$
\left\|x_{m_{k}}-z\right\|<\left\|x_{m_{k}+1}-z\right\| \quad \text { and } \quad\left\|x_{k}-z\right\| \leq\left\|x_{m_{k}+1}-z\right\|
$$

for all $k \in \mathbb{N}$. This, together with (4.7), implies that

$$
\beta_{m_{k}}\left(1-\beta_{m_{k}}\right) g\left(\left\|x_{m_{k}}-T^{m_{k}} x_{m_{k}}\right\|\right) \leq\left\|x_{m_{k}}-z\right\|^{2}-\left\|x_{m_{k}+1}-z\right\|^{2}+\alpha_{m_{k}} M_{2} \leq \alpha_{m_{k}} M_{2}
$$

for all $k \in \mathbb{N}$. Then, by conditions (a) and (c) and the properties of $g$, we get

$$
\lim _{k \rightarrow \infty}\left\|x_{m_{k}}-T^{m_{k}} x_{m_{k}}\right\|=0
$$


By the same argument, as in Case 1, we arrive at

$$
\limsup _{k \rightarrow \infty}\left\langle u-z, J\left(x_{m_{k}}-z\right)\right\rangle=\limsup _{k \rightarrow \infty}\left\langle u-z, J\left(x_{m_{k}+1}-z\right)\right\rangle \leq 0
$$

Next, it follows from (4.5) that

$$
\left\|x_{m_{k}+1}-z\right\|^{2} \leq\left(1-\alpha_{m_{k}}\right)\left\|x_{m_{k}}-z\right\|^{2}+\alpha_{m_{k}}\left\langle u-z, J\left(x_{m_{k}+1}-z\right)\right\rangle .
$$

Since $\left\|x_{m_{k}}-z\right\| \leq\left\|x_{m_{k}+1}-z\right\|$, we conclude that

$$
\begin{aligned}
\alpha_{m_{k}}\left\|x_{m_{k}}-z\right\|^{2} & \leq\left\|x_{m_{k}}-z\right\|^{2}-\left\|x_{m_{k}+1}-z\right\|^{2}+\alpha_{m_{k}}\left\langle u-z, J\left(x_{m_{k}+1}-z\right)\right\rangle \\
& \leq 2 \alpha_{m_{k}}\left\langle u-z, J\left(x_{m_{k}+1}-z\right)\right\rangle .
\end{aligned}
$$

In particular, since $\alpha_{m_{k}}>0$, we obtain

$$
\left\|x_{m_{k}}-z\right\|^{2} \leq\left\langle u-z, J\left(x_{m_{k}+1}-z\right)\right\rangle
$$

and hence

$$
\lim _{k \rightarrow \infty}\left\|x_{m_{k}}-z\right\|=0
$$

This, together with (4.13), implies that

$$
\lim _{k \rightarrow \infty}\left\|x_{m_{k}+1}-z\right\|=0
$$

On the other hand, we have $\left\|x_{k}-z\right\| \leq\left\|x_{m_{k}+1}-z\right\|$ for all $k \in \mathbb{N}$, which implies that $x_{k} \rightarrow z$ as $k \rightarrow \infty$. Thus, we have $x_{n} \rightarrow z$ as $n \rightarrow \infty$, which completes the proof.

Let $C$ be a nonempty, closed and convex subset of a Hilbert space $H$, and let $T: C \rightarrow C$ be a nonspreading mapping such that $F(T) \neq \emptyset$. For any real number $\beta \in(0,1)$, we define a mapping $T_{\beta}: C \rightarrow C$ by

$$
T_{\beta} x=(1-\beta) I x+\beta T x \quad(x \in C),
$$

where $I$ is the identity mapping on $H$. It is easy to verify that $T_{\beta}$ is a nonspreading mapping and $F\left(T_{\beta}\right)=F(T)$. Therefore, in view of Proposition 2.1, $F\left(T_{\beta}\right)$ is closed and convex. The following strong convergence result provides an affirmative answer to open Question 1.1 in the case where the mapping $T$ is nonspreading. It is worth mentioning that our method of proof is different from that in [19] and can be applied in uniformly convex Banach spaces. In fact, an answer will be given for more general spaces than Hilbert spaces.

Corollary 4.1 Let E be a real uniformly convex Banach space which admits the weakly sequentially continuous duality mapping $J$, and let $C$ be a nonempty, closed and convex subset of E. Let $T: C \rightarrow C$ be a nonspreading mapping such that $F:=F(T) \neq \emptyset$. Let $\left\{\alpha_{n}\right\}_{n \in \mathbb{N}}$ be a sequence in $[0,1]$ satisfying the following control conditions:

(a) $\lim _{n \rightarrow \infty} \alpha_{n}=0$;

(b) $\sum_{n=1}^{\infty} \alpha_{n}=\infty$. 
For any real number $\beta \in(0,1)$, let $\left\{x_{n}\right\}_{n \in \mathbb{N}}$ be a sequence generated by

$$
\left\{\begin{array}{l}
u \in C, \quad x_{1} \in C \quad \text { chosen arbitrarily, } \\
y_{n}=(1-\beta) x_{n}+\beta T x_{n} \\
x_{n+1}=\alpha_{n} u+\left(1-\alpha_{n}\right) y_{n}
\end{array}\right.
$$

Then the sequence $\left\{x_{n}\right\}_{n \in \mathbb{N}}$ converges strongly to $Q_{F} u$, where $Q_{F}$ is the sunny nonexpansive retraction from $E$ onto $F$.

Corollary 4.2 Let $C$ be a nonempty, closed and convex subset of a Hilbert space $H$, and let $T: C \rightarrow C$ be a nonspreading mapping such that $F:=F(T) \neq \emptyset$. Let $\left\{\alpha_{n}\right\}_{n \in \mathbb{N}}$ be a sequence in $[0,1]$ satisfying the following control conditions:

(a) $\lim _{n \rightarrow \infty} \alpha_{n}=0$;

(b) $\sum_{n=1}^{\infty} \alpha_{n}=\infty$.

For any real number $\beta \in(0,1)$, let $T_{\beta}: C \rightarrow C$ be defined by (4.15). Let $\left\{x_{n}\right\}_{n \in \mathbb{N}}$ be a sequence generated by

$$
\left\{\begin{array}{l}
u \in C, \quad x_{1} \in C \quad \text { chosen arbitrarily, } \\
x_{n+1}=\alpha_{n} u+\left(1-\alpha_{n}\right) T_{\beta} x_{n} .
\end{array}\right.
$$

Then the sequence $\left\{x_{n}\right\}_{n \in \mathbb{N}}$ converges strongly to $P_{F} u$, where $P_{F}$ is the metric projection from $H$ onto $F$.

Theorem 4.3 Let E be a uniformly convex Banach space which admits the weakly sequentially continuous duality mapping $J$, and let $C$ be a nonempty, closed and convex subset of $E$. Let $T_{1}: C \rightarrow C$ be an asymptotically nonspreading mapping, and let $T_{2}: C \rightarrow C$ be a nonexpansive mapping such that $F:=F\left(T_{1}\right) \cap F\left(T_{2}\right) \neq \emptyset$. Let $\left\{\alpha_{n}\right\}_{n \in \mathbb{N}},\left\{\beta_{n, 1}\right\}_{n \in \mathbb{N}},\left\{\beta_{n, 2}\right\}_{n \in \mathbb{N}}$, $\left\{\beta_{n, 3}\right\}_{n \in \mathbb{N}}$ be sequences in $[0,1]$ satisfying the following control conditions:

(a) $\lim _{n \rightarrow \infty} \alpha_{n}=0$;

(b) $\sum_{n=1}^{\infty} \alpha_{n}=\infty$;

(c) $\beta_{n, 1}+\beta_{n, 2}+\beta_{n, 3}=1, \forall n \in \mathbb{N}$;

(d) $\liminf _{n \rightarrow \infty} \beta_{n, j} \beta_{n, 3}>0, j=1,2$.

Let $\left\{x_{n}\right\}_{n \in \mathbb{N}}$ be a sequence generated by

$$
\left\{\begin{array}{l}
u \in C, \quad x_{1} \in C \quad \text { chosen arbitrarily, } \\
y_{n}=\beta_{n, 1} T_{1} x_{n}+\beta_{n, 2} T_{2} x_{n}+\beta_{n, 3} x_{n} \\
x_{n+1}=\alpha_{n} u+\left(1-\alpha_{n}\right) y_{n}
\end{array}\right.
$$

Then the sequence $\left\{x_{n}\right\}_{n \in \mathbb{N}}$ defined in (4.16) converges strongly to $Q_{F} u$, where $Q_{F}$ is a sunny nonexpansive retraction from $E$ onto $F$.

Proof We divide the proof into several steps.

Since $T$ is a quasi-nonexpansive mapping, so we have $F$ is closed and convex. Set

$$
z=Q_{F} u
$$


Step 1. We prove that the sequences $\left\{x_{n}\right\}_{n \in \mathbb{N}},\left\{y_{n}\right\}_{n \in \mathbb{N}},\left\{T_{1} x_{n}\right\}_{n \in \mathbb{N}}$ and $\left\{T_{2} x_{n}\right\}_{n \in \mathbb{N}}$ are bounded.

We first show that $\left\{x_{n}\right\}_{n \in \mathbb{N}}$ is bounded.

Let $p \in F$ be fixed. In view of Lemma 2.5 , there exists a continuous, strictly increasing and convex function $g:[0, \infty) \rightarrow[0, \infty)$ with $g(0)=0$ such that

$$
\begin{aligned}
\left\|y_{n}-p\right\|^{2}= & \left\|\beta_{n, 1} T_{1} x_{n}+\beta_{n, 2} T_{2} x_{n}+\beta_{n, 3} x_{n}-p\right\|^{2} \\
\leq & \beta_{n, 1}\left\|T_{1} x_{n}-p\right\|^{2}+\beta_{n, 2}\left\|T_{2} x_{n}-p\right\|^{2}+\beta_{n, 3}\left\|x_{n}-p\right\|^{2} \\
& -\beta_{n, j} \beta_{n, 3} g\left(\left\|x_{n}-T_{j} x_{n}\right\|\right) \\
\leq & \beta_{n, 1}\left\|x_{n}-p\right\|^{2}+\beta_{n, 2}\left\|x_{n}-p\right\|^{2}+\beta_{n, 3}\left\|x_{n}-p\right\|^{2} \\
& -\beta_{n, j} \beta_{n, 3}\left\|x_{n}-T_{j} x_{n}\right\|^{2} \\
= & \left\|x_{n}-p\right\|^{2}-\beta_{n, j} \beta_{n, 3} g\left(\left\|x_{n}-T_{j} x_{n}\right\|\right) \\
\leq & \left\|x_{n}-p\right\|^{2}, \quad j=1,2 .
\end{aligned}
$$

This implies that

$$
\begin{aligned}
\left\|x_{n+1}-p\right\| & =\left\|\alpha_{n} u+\left(1-\alpha_{n}\right) y_{n}-p\right\| \\
& \leq \alpha_{n}\|u-p\|+\left(1-\alpha_{n}\right)\left\|y_{n}-p\right\| \\
& \leq \alpha_{n}\|u-p\|+\left(1-\alpha_{n}\right)\left\|x_{n}-p\right\| \\
& \leq \max \left\{\|u-p\|,\left\|x_{n}-p\right\|\right\} .
\end{aligned}
$$

By induction, we obtain

$$
\left\|x_{n+1}-p\right\| \leq \max \left\{\|u-p\|,\left\|x_{1}-p\right\|\right\}
$$

for all $n \in \mathbb{N}$. This implies that the sequence $\left\{\left\|x_{n}-p\right\|\right\}_{n \in \mathbb{N}}$ is bounded and hence the sequence $\left\{x_{n}\right\}_{n \in \mathbb{N}}$ is bounded. This, together with (4.16), implies that the sequences $\left\{y_{n}\right\}_{n \in \mathbb{N}}$, $\left\{T_{1} x_{n}\right\}_{n \in \mathbb{N}}$ and $\left\{T_{2} x_{n}\right\}_{n \in \mathbb{N}}$ are bounded too.

Step 2 . We prove that for any $n \in \mathbb{N}$,

$$
\left\|x_{n+1}-z\right\|^{2} \leq\left(1-\alpha_{n}\right)\left\|x_{n}-z\right\|^{2}+2 \alpha_{n}\left\langle u-z, J\left(x_{n+1}-z\right)\right\rangle .
$$

Let us show (4.18). For each $n \in \mathbb{N}$ and $j=1,2$, in view of (4.17), we obtain

$$
\left\|y_{n}-z\right\|^{2} \leq\left\|x_{n}-z\right\|^{2}-\beta_{n, j} \beta_{n, 3} g\left(\left\|x_{n}-T_{j} x_{n}\right\|\right) .
$$

This implies that

$$
\begin{aligned}
\left\|x_{n+1}-z\right\|^{2} & =\left\|\alpha_{n} u+\left(1-\alpha_{n}\right) y_{n}-z\right\|^{2} \\
& \leq \alpha_{n}\|u-z\|^{2}+\left(1-\alpha_{n}\right)\left\|y_{n}-z\right\|^{2} \\
& \leq \alpha_{n}\|u-z\|^{2}+\left(1-\alpha_{n}\right)\left[\left\|x_{n}-z\right\|^{2}-\beta_{n, j} \beta_{n, 3} g\left(\left\|x_{n}-T_{j} x_{n}\right\|\right)\right] .
\end{aligned}
$$


Let $M_{3}:=\sup \left\{\left|\|u-z\|^{2}-\left\|x_{n}-z\right\|^{2}\right|+\beta_{n, j} \beta_{n, 3} g\left(\left\|x_{n}-T_{j} x_{n}\right\|\right): n \in \mathbb{N}, j=1,2\right\}$. It follows from (4.19) that

$$
\beta_{n, j} \beta_{n, 3} g\left(\left\|x_{n}-T_{j} x_{n}\right\|\right) \leq\left\|x_{n}-z\right\|^{2}-\left\|x_{n+1}-z\right\|^{2}+\alpha_{n} M_{3}, \quad j=1,2 .
$$

In view of Lemma 2.2 and (4.17), we obtain

$$
\begin{aligned}
\left\|x_{n+1}-z\right\|^{2} & =\left\|\alpha_{n} u+\left(1-\alpha_{n}\right) y_{n}-z\right\|^{2} \\
& \leq\left\|\alpha_{n} u+\left(1-\alpha_{n}\right) y_{n}-z-\alpha_{n}(u-z)\right\|^{2}+2\left\langle\alpha_{n}(u-z), J\left(x_{n+1}-z\right)\right\rangle \\
& =\left\|\left(1-\alpha_{n}\right)\left(y_{n}-z\right)\right\|^{2}+2 \alpha_{n}\left\langle u-z, J\left(x_{n+1}-z\right)\right\rangle \\
& =\left(1-\alpha_{n}\right)\left\|y_{n}-z\right\|^{2}+2 \alpha_{n}\left\langle u-z, J\left(x_{n+1}-z\right)\right\rangle \\
& \leq\left(1-\alpha_{n}\right)\left\|x_{n}-z\right\|^{2}+2 \alpha_{n}\left\langle u-z, J\left(x_{n+1}-z\right)\right\rangle .
\end{aligned}
$$

Step 3. We prove that $x_{n} \rightarrow z$ as $n \rightarrow \infty$.

We discuss the following two possible cases.

Case 1. If $\left\{\left\|x_{n}-z\right\|\right\}_{n \in \mathbb{N}}$ is eventually decreasing, then there exists $n_{0} \in \mathbb{N}$ such that the sequence $\left\{\left\|x_{n}-z\right\|\right\}_{n=n_{0}}^{\infty}$ is decreasing. Thus, the sequence $\left\{\left\|x_{n}-z\right\|\right\}_{n \in \mathbb{N}}$ is convergent and hence $\left\|x_{n}-z\right\|^{2}-\left\|x_{n+1}-z\right\|^{2} \rightarrow 0$ as $n \rightarrow \infty$. This, together with condition (d) and (4.20), implies that

$$
\lim _{n \rightarrow \infty} g\left(\left\|x_{n}-T_{j} x_{n}\right\|\right)=0, \quad j=1,2
$$

From the properties of $g$, it follows that

$$
\lim _{n \rightarrow \infty}\left\|x_{n}-T_{j} x_{n}\right\|=0, \quad j=1,2
$$

On the other hand, we have

$$
y_{n}-x_{n}=\beta_{n, 1}\left(T_{1} x_{n}-x_{n}\right)+\beta_{n, 2}\left(T_{2} x_{n}-x_{n}\right) \quad \text { and } \quad x_{n+1}-y_{n}=\alpha_{n}\left(u-y_{n}\right) .
$$

This implies that

$$
\lim _{n \rightarrow \infty}\left\|x_{n}-y_{n}\right\|=0 \quad \text { and } \quad \lim _{n \rightarrow \infty}\left\|x_{n+1}-y_{n}\right\|=0
$$

By the triangle inequality, we conclude that

$$
\left\|x_{n+1}-x_{n}\right\| \leq\left\|x_{n+1}-y_{n}\right\|+\left\|y_{n}-x_{n}\right\|
$$

It follows from (4.22) that

$$
\lim _{n \rightarrow \infty}\left\|x_{n+1}-x_{n}\right\|=0
$$

Since $\left\{x_{n}\right\}_{n \in \mathbb{N}}$ is bounded, there exists a subsequence $\left\{x_{n_{i}}\right\}_{i \in \mathbb{N}}$ of $\left\{x_{n}\right\}_{n \in \mathbb{N}}$ such that $x_{n_{i}+1} \rightarrow$ $y \in C$ as $i \rightarrow \infty$. In view of Proposition 3.1 and (4.21), we conclude that $y \in F$. This, to- 
gether with Lemma 2.1, implies that

$$
\begin{aligned}
\limsup _{n \rightarrow \infty}\left\langle u-z, J\left(x_{n+1}-z\right)\right\rangle & =\lim _{i \rightarrow \infty}\left\langle u-z, J\left(x_{n_{i}+1}-z\right)\right\rangle \\
& =\langle u-z, J(y-z)\rangle \\
& \leq 0
\end{aligned}
$$

Thus we have the desired result by Lemma 2.3 .

Case 2. By the same method, as in the proof of Theorem 4.2, we can prove that $x_{n} \rightarrow z$ as $n \rightarrow \infty$. This completes the proof.

Remark 4.1 (1) Note that [18, Theorem 4.1] is a weak convergence result and that our Theorem 4.3 is a strong convergence result. However, it is worth pointing out that the method of proving Theorem 4.3 is very different from the method of proving Theorem 4.1 of [18].

(2) In most cases, strong convergence is more desirable than weak convergence.

\section{Competing interests}

The author declares that they have no competing interests.

\section{Acknowledgements}

The author would like to thank the editor and the referees for sincere evaluation and constructive comments which improved the paper considerably. This work was conducted with a postdoctoral fellowship at the National Sun Yat-sen University of Kaohsiung, Taiwan.

Received: 30 July 2013 Accepted: 13 August 2013 Published: 28 August 2013

\section{References}

1. Takahashi, W: Nonlinear Functional Analysis: Fixed Point Theory and Its Applications. Yokahama Publishers, Yokahama (2000)

2. Gossez, JP, Dozo, EL: Some geometric properties related to the fixed point theory for nonexpansive mappings. Pac. J. Math. 40, 565-573 (1972)

3. Geobel, K, Kirk, WA: Topics on Metric Fixed-Point Theory. Cambridge Studies in Advanced Mathematics, vol. 28 Cambridge University Press, Cambridge (1990)

4. Mann, WR: Mean value methods in iteration. Proc. Am. Math. Soc. 4, 506-510 (1953)

5. Halpern, B: Fixed points of nonexpanding mappings. Bull. Am. Math. Soc. 73, 957-961 (1967)

6. Reich, S: Weak convergence theorems for nonexpansive mappings in Banach spaces. J. Math. Anal. Appl. 67, 274-276 (1979)

7. Nilsrakoo, W, Saejung, S: Strong convergence theorems by Halpern-Mann iterations for relatively nonexpansive mappings in Banach spaces. Appl. Math. Comput. 217, 6577-6586 (2011)

8. Moudafi, A: Krasnoselski-Mann iteration for hierarchical fixed-point problems. Inverse Probl. 23, 1635-1640 (2007)

9. Suzuki, T: Strong convergence of Krasnoselskii and Mann type sequences for one parameter nonexpansive semigroups without Bochner integrals. J. Math. Anal. Appl. 305, 227-239 (2005)

10. Takahashi, W, Kim, GE: Approximating fixed points of nonexpansive mappings in Banach spaces. Math. Jpn. 48, 1-9 (1998)

11. Aoyama, K, Kimura, Y, Takahashi, W, Toyoda, M: Approximation of common fixed points of a countable family of nonexpansive mappings in a Banach space. Nonlinear Anal. 67, 2350-2360 (2007)

12. Hicks, TL, Kubicek, JR: On the Mann iterative process in Hilbert spaces. J. Math. Anal. Appl. 59, 498-504 (1977)

13. Song, Y, Chai, X: Halpern iteration for firmly type nonexpansive mappings. Nonlinear Anal. 71, 4500-4506 (2009)

14. Saejung, S: Halpern's iteration in Banach spaces. Nonlinear Anal. 73, 3431-3439 (2010)

15. Kohsaka, F, Takahashi, W: Fixed point theorems for a class of nonlinear mappings related to maximal monotone operators in Banach spaces. Arch. Math. 91, 166-177 (2008)

16. Kohsaka, F, Takahashi, W: Existence and approximation of fixed points of firmly nonexpansive-type mappings in Banach spaces. SIAM J. Optim. 19, 824-835 (2008)

17. Kurokawa, Y, Takahashi, W: Weak and strong convergence theorems for nonspreading mappings in Hilbert spaces. Nonlinear Anal. 73, 1562-1568 (2010)

18. lemoto, S, Takahashi, W: Approximating common fixed points of nonexpansive mappings and nonspreading mappings in a Hilbert space. Nonlinear Anal. 71, e2080-e2089 (2009)

19. Osilike, MO, Isiogugu, FO: Weak and strong convergence theorems of nonspreading-type mappings. Nonlinear Anal. 74, 1814-1822 (2011) 
20. Takahashi, W, Wong, N-C, Yao, J-C: Fixed point theorems and convergence theorems for generalized nonspreading mappings in Banach spaces. J. Fixed Point Theory Appl. (2012). doi:10.1007/s11784-012-0074-3

21. Igarashi, T, Takahashi, W, Tanaka, K: Weak convergence theorems for nonspreading mappings and equilibrium problems. In: Akashi, S, Takahashi, W, Tanaka, T (eds.) Nonlinear Analysis and Optimization, vol. , pp. 75-85. Yokahama Publishers, Yokohama (2009)

22. Goebel, K, Reich, S: Uniform Convexity, Hyperbolic Geometry, and Nonexpansive Mappings. Dekker, New York (1984)

23. $\mathrm{Xu}, \mathrm{H}-\mathrm{K}, \mathrm{Kim}, \mathrm{TK}$ : Convergence of hybrid steepest-descent methods for variational inequalities. J. Optim. Theory Appl. 119(1), 185-201 (2003)

24. Maingé, PE: Strong convergence of projected subgradient methods for nonsmooth and nonstrictly convex minimization. Set-Valued Anal. 16, 899-912 (2008)

25. Cho, YJ, Zhou, HY, Guo, G: Weak and convergence theorems for three-step iterations with errors for asymptotically nonexpansive mappings. Comput. Math. Appl. 47, 707-717 (2004)

26. $\mathrm{Xu}, \mathrm{H}-\mathrm{K}$ : Inequalities in Banach spaces with applications. Nonlinear Anal. 16, 1127-1138 (1991)

doi:10.1186/1687-1812-2013-228

Cite this article as: Naraghirad: On an open question of Takahashi for nonspreading mappings in Banach spaces.

Fixed Point Theory and Applications 2013 2013:228.

\section{Submit your manuscript to a SpringerOpen ${ }^{\ominus}$ journal and benefit from:}

- Convenient online submission

- Rigorous peer review

- Immediate publication on acceptance

- Open access: articles freely available online

- High visibility within the field

- Retaining the copyright to your article 